TRANSMUTACIONES DEL LIRISMO EN LA OBRA DE ROBERTO BOLAÑO

\title{
Transmutations of lyricism in the works of Roberto Bolaño
}

\author{
FLORENCE OLIVIER \\ Université de LA SORBONNE NOUVELLE, PARIS 3 \\ flordolivo@wanadoo.fr
}

\begin{abstract}
Resumen: La desconfianza hacia el lirismo de los "puritanos revolucionarios", la convicción de haber descubierto un "lirismo diferente" guió los pasos del joven infrarrealista Roberto Bolaño y lo llevó primero a explorar un entredós entre prosa y poesía y más adelante entre narrativa y poesía. De esa exploración intenta dar cuenta este ensayo, leyendo la obra como un tejido continuo, deteniéndose en poemas de los años ochenta, en el "manifiesto infrarrealista" de 1977, en algunos cuentos de Putas asesinas en los que muta la invocación lírica y en ese objeto literario indefinido y mutante que, con mínimos cambios, se manifiesta ora como "Gente que se aleja", poesía, ora como Amberes, novela.
\end{abstract}

Palabras clave: lirismo, prosa, entredós, invocación, transmutación

Abstract: Suspicious of the lyricism of "puritans revolutionaries" and convinced that he had himself discovered a "different lyricism", the Young infrarrealista Roberto Bolaño went on to explore the interspace between prose and poetry and, later, between poetry and narrative. Reading the work of the writer as a continuum, the present essay strives to reflect on this exploration, with particular attention to his 80 's poems, to the "infrarrealista manifesto" of 1977, and the stories of Putas asesinas, in which lyrical invocation is transmuted into the evocation of others writers as correspondents or dreamt characters, and to a mutant literary text that, with minimal changes, might manifest itself as poetry ("Gente que se aleja") or in the form of a novel (Amberes).

Keywords: lyricism, prose, interspace, invocation, transmutation 
Aquel joven poeta infrarrealista, Roberto Bolaño su nombre, dio el salto mortal y llegó a la novela. Versión breve y desde luego mitificada de la singular historia del escritor. Aquel joven poeta infrarrealista ya escribía cuentos en los años setenta, a decir de algún compañero de andanzas. Aquel joven poeta infrarrealista escribía, ya desde los setenta, poesía narrativa y, cuidado, no se trataba de la llamada prosa poética. Versión más larga y más exacta de la búsqueda literaria de Roberto Bolaño. Aquel joven poeta, recién alejado y separado por un océano del grupo infrarrealista, ya instalado en Barcelona, desafiante, dejaba en claro entre 1979 y 1980, que su lirismo era "diferente":

\author{
Ésta es la pura verdad \\ Me he criado al lado de puritanos revolucionarios \\ He sido criticado ayudado empujado por héroes \\ de la poesía lírica \\ y del balancín de la muerte. \\ Quiero decir que mi lirismo es DIFERENTE \\ (ya está todo expresado pero permitidme \\ añadir algo más). \\ Nadar en los pantanos de la cursilería \\ es para mí como un Acapulco de mercurio \\ un Acapulco de sangre de pescado \\ una Disneylandia submarina \\ En donde soy en paz conmigo. (Bolaño, 2007: 18)
}

Semejante vindicación de un lirismo inesperadamente asociado por una metáfora hilada a la sangre de pescado, a la luz refractaria del trópico mexicano, a un paisaje artificial, se rebela ante las exigencias de la poesía comprometida de los "puritanos revolucionarios". El poema también guarda el impulso del manifiesto infrarrealista que Roberto Bolaño firmó y publicó en México en 1976 e incluso conserva la tipografía propia de la proclama con las mayúsculas que asientan la calificación del lirismo como "DIFERENTE". Ese punto de partida programático, apenas alusivo al deseo de distinguirse del lirismo imperante entre los poetas de la izquierda latinoamericana para hallar otro, distinto, podría señalar la encrucijada que presidió la empresa poética del escritor y lo llevó a la narración de ficciones en cuentos y novelas. En los primeros años barceloneses, tras la experiencia colectiva mexicana, consigna sus poemas y fragmentos en unos cuadernos titulados "Diario de vida I", "Diario de vida II", "Diario de vida II", ${ }^{1}$ cuya simple existencia da cuenta de la estrecha relación que seguía viendo el poeta, fiel a la postura vanguardista, entre arte y vida, entre la escritura y la experiencia cotidiana. En una tardía entrevista filmada durante la Feria Internacional del Libro en

\footnotetext{
${ }^{1}$ Véanse las referencias a los archivos del escritor que proporciona Carolina López en la nota final a la edición de la obra poética reunida en La Universidad Desconocida. Carolina López, "Breve historia del libro", La Universidad Desconocida, Barcelona, Anagrama, 2007, pp. 457-459.
} 
Santiago de Chile en 1999, vuelve Roberto Bolaño sobre la cuestión del lirismo para afirmar: “...además, Yo, como poeta, no soy nada lírico, soy totalmente prosaico, cotidiano. Mi poeta favorito es Nicanor Parra. Nicanor Parra ya lo dice, él no habla de crepúsculos ni de damas recortadas sobre el horizonte sino de comidas, y luego de ataúdes, y ataúdes y ataúdes, lo repite" (Warnken, 1999) "Nada lírico" será un decir, y más propiamente hemos de entender que Bolaño apela de nuevo a un lirismo diferente del asentado por el Neruda de los Veinte poemas de amor y una canción desesperada ${ }^{2}$ al que a todas luces alude como contra ejemplo Nicanor Parra a quien el entrevistado cita de memoria.

¿Prosaico? ¿Lírico? Entre los polos opuestos o las estéticas encontradas a los que remiten tales adjetivos gastados, Bolaño elige el primero para mayor claridad y juguetona provocación, reduciendo el lirismo a su definición más acartonada y sin duda al impudor de la expresión sentimental impostada de Su Majestad el Yo. En 2001, al escribir una introducción para el catálogo de una exposición de los "Artefactos" de Parra en Madrid, no sólo reitera su convicción acerca de la renovación poética que emprendió y logró el autor de los Poemas y antipoemas sino que, partiendo de su ejemplo, augura el futuro de la poesía como forma híbrida, comparándola con la hibridez de la prosa narrativa. E hibridez significa, entre otras posibles interpretaciones, prosaísmo lírico o lirismo prosaico, un oxímoron por donde se le mire, llámese antipoesía o de otro modo, que en nada está reñido con la poesía, como lo subrayó el propio Nicanor Parra en su "Nota sobre la lección de la antipoesía" (Parra, 1985), y que, según recuerda Bolaño, no se olvida ni de reinterpretar a Lautréamont ni de resucitar la subversión primera del surrealismo:

La poesía de las primeras décadas del siglo XXI será una poesía híbrida, como ya lo está siendo la narrativa. Posiblemente nos encaminamos, con una lentitud espantosa, hacia nuevos temblores formales. En ese futuro incierto nuestros hijos contemplarán el encuentro sobre una mesa de operaciones del poeta que duerme en una silla con el pájaro negro del desierto, aquel que se alimenta de los parásitos de los camellos. En cierta ocasión, en los últimos años de su vida, Breton habló de la necesidad de que el surrealismo pasara a la clandestinidad, se sumergiera en las cloacas de las ciudades y de las bibliotecas. Luego no volvió a tocar nunca más el tema. No importa quién lo dijo: LA HORA DE SENTAR CABEZA NO LLEGARÁ JAMÁS. (Bolaño, 2004b: 93)

En la misma entrevista filmada en la Feria Internacional del Libro de Santiago en 1999, a la pregunta que se le hace sobre la posibilidad de experimentar un éxtasis similar a los buscados por Baudelaire o Rimbaud a la lectura de los

\footnotetext{
${ }^{2}$ Véase en especial el poema 2.
} 
antipoemas de Parra o de alguna novela, contesta Bolaño: "Yo creo que la mejor poesía de este siglo está escrita en prosa. Hay páginas del Ulises de Joyce, o de Proust o de Faulkner que han tensado el arco como no lo ha hecho la poesía en este siglo, donde realmente te das cuenta de que el escritor se ha metido por una senda en donde nadie antes se había metido" (Warnken, 1999).

El ideal vanguardista de la exploración de lo nuevo e ignoto, ya expresado por Baudelaire como fatalidad del deseo moderno en el verso final de "El viaje", se aúna al rechazo de lo razonable, mesurado y cauto en estos comentarios de Bolaño que señala, de manera nada ingenua, el norte de la búsqueda poética en el siglo XX por el lado de la novela $\mathrm{y}$, en un quiasmo imaginativo, su equivalente en la poesía del XXI. Bastarían para esclarecer cómo, en unos progresivos deslizamientos del placer, y la disciplina, de la elaboración de la propia obra, fue desplazándose por el terreno del entredós entre prosa y lirismo. En un ensayo sobre lo que él considera como "algunos infrarrealismos" Heriberto Yépez se funda en el ya citado texto de Bolaño sobre Nicanor Parra y la futura hibridez de la poesía de las primeras décadas del siglo XXI para afirmar:

Esta mescolanza la conservó Bolaño en su prosa. Es uno de sus rasgos distintivos. Por otra parte, no sólo el lenguaje novelístico de Bolaño es una mezcla -en la mejor tradición latinoamericana- de lenguaje culto y popular sino también el paso mismo de la poesía hacia la novela es la transmutación de formas ocurrida durante su existencia. Poco se ha investigado de este paso de la poesía hacia la novela, un atajo que no solamente concierne a muchos novelistas, que primero fueron poetas y después concluyeron en la novela sino que también envuelve a la historia propia de la novela como estructura histórica. No lo olvidemos: la novela es una mutación que sufrió la poesía. (Yépez, 2009)

Si bien la última observación atañe a una historia literaria que sólo podría definirse como historia de larga duración y si, por otro lado, podría agregarse que no faltan, entre los poetas, los autores de alguna novela ,por lo general una sola, excepcional, la noción de "transmutación de formas" que invoca el crítico parece afortunada. Aunque, remedando al propio Heriberto Yépez cuando abre el infrarrealismo a sus realidades múltiples, para mayor justicia habría de concebirse la transmutación como una serie de transmutaciones, una multiplicación, extensión y ramificación de formas a lo largo del quehacer del poeta y narrador.

Para pensar el paso de la poesía a la novela en la obra de Roberto Bolaño tal vez se debería empezar por considerar la totalidad de sus escritos como un tejido continuo que se presta no sólo a la transmutación de las formas sino al viaje o la migración de sus elementos de una a otra forma. De ese continuo tejido, el escritor extrae composiciones, va buscándoles la 
forma y la dimensión precisas, a medida que amartilla su lirismo prosaico e irónico en el yunque de la escritura, resolviéndose en los años noventa a narrar las aventuras de la formación del poeta joven que dejó de ser, combatiendo pie a pie por el honor de los poetas desde la novela, usando las armas de las letras contra las letras mismas para la sátira de los medios literarios, jugando con el canon como si fuese rompecabezas y explorando la Ciudad de la Literatura, que no sólo la Biblioteca.

Así fue creciendo la obra, y si tanto se ha hablado de su dinámica fractal, de las ampliaciones de fragmentos o capítulos de ciertas obras para lograr nuevas piezas autónomas como las novelas breves Estrella distante y Amuleto, también podría pensarse como una inmensa composición rítmica, felizmente inconclusa, abierta a una lectura móvil.

Una de las luchas de Roberto Bolaño parecería ser, durante las tres décadas y tres años en los que escribe, la constante batalla por exorcizar cierto lirismo e inventar el suyo propio, el que cree haber distinguido, elegido y establecido desde finales de los setenta, y tal vez antes, desde las primeras publicaciones individuales y colectivas de la etapa mexicana e infrarrealista. Para ello, no sólo practica desde un inicio la escritura de la poesía a modo de prosaico diario de la vida cotidiana, sino que el Yo escrito debe entrar en un proceso de disolución y diseminación cuya forma más visible será más tarde la escritura de ficciones con gran variedad de personajes y con ese alter ego ficticio ideal y carnavalizado, Arturo Belano, que pasa a ser una figura tan recurrente como esquiva e inasible en las novelas y algún que otro cuento. A menudo limitado al papel del narrador de primera mano -en Estrella distante-, o de narrador imperceptible y conjetural -como lo indicaría una nota aislada e inédita del autor sobre quién cuenta la vastísima 2666-, ${ }^{3}$ Belano desempeña, junto con Ulises Lima, el papel de personaje central en Los detectives salvajes. Central, sí, pero siempre visto de manera sesgada y por ende irónica, siempre enigmático y paradójico sujeto a costa de ser objeto, imagen tal vez de esa rara identidad intersubjetiva del "YO es otro", "YO somos otros" que es el autor y hacedor. Uno de sus avatares menos personalizados, suerte de crisálida de Belano o de identidad cifrada de Bolaño, es B, protagonista de algunos cuentos de Llamadas telefónicas y Putas asesinas que alterna con Arturo Belano, presente en otros, en el espacio de las ficciones reunidas en esos dos volúmenes. Si Bolaño no llegó a crear heterónimos al modo de un Pessoa, sí declinó, en una como gramática generativa de la identidad propia, múltiples avatares del Yo, ensayando y ejercitando distintos grados y variantes de la autorrepresentación, multiplicando los autorretratos, metamorfoseando la autobiografía en autoficción. El locutor de los poemas se empeña en

\footnotetext{
3 Véase Ignacio Echevarría, "Nota a la primera edición”, en Roberto Bolaño, 2666, Barcelona, Anagrama, 2004, p. 1.125: "Entre las notas de Bolaño relativas a 2666 se lee, en un apunte aislado: "El narrador de 2666 es Arturo Belano". Y en otro lugar añade, con la indicación "para el final de 2666": "Y esto es todo, amigos. Todo lo he hecho, todo lo he vivido. Si tuviera fuerzas, me pondría a llorar. Se despide de ustedes, Arturo Belano".
} 
distanciarse de sí mismo; el Bolaño crítico, autor de discursos, crónicas, reseñas, ensayos y neopanfletos, ya se escenifica a sí mismo, se narra y se desplaza entre distintas figuraciones pese a su aparente situarse en el grado cero del disfraz del Yo; en la vía tercera de la ficción, por fin desaparece el Yo tras su conversión en otros ficticios, llámense B o Belano. Cada uno de estos espectros o variantes figurales del autor se mueve por un mundo donde convive con otros, de identidades precisas e inscritas en la coherencia de un universo referencial realista o imaginario: cuando $B$ personaje ama a $X$ en Sevilla, visita a $\mathrm{M}$ en Bélgica o mantiene una solapada rivalidad con el escritor A en Madrid, Arturo Belano se inicia a la vida poética en México con Ulises Lima y los demás viscerrealistas, provistos todos de nombres ficticios completos, mientras el Yo de la poesía, que aborrecería la académica denominación de "hablante lírico", nombra a sus amigos y amantes reales, a su hijo Lautaro y su madre Victoria Ávalos y hasta a su padre León Bolaño.

Sólo que incluso en la obra poética el Yo se convierte en segunda o tercera persona y por ende en personaje, ora en un gesto de irónica auto mitificación que lo reinventa como estoico poeta troyano en un título como "San Roberto de Troya", que data de los años ochenta, ora en unos como conjuros del destino propio en la madurez de los noventa, retratado en el poema "Los años" el muchacho latinoamericano que fue quien escribe, reescrito en clave alegórica el regreso real a Chile en "El regreso de Roberto Bolaño" o escrito el retorno en sueños a los años de juventud en México en "Devoción de Roberto Bolaño", " poema amuleto que ampara al poeta restituyéndole su valor ante la enfermedad.

Desde luego para el lector/escritor que fue y sigue siendo póstumamente el autor, los acompañantes e interlocutores de los avatares del Yo en las distintas vertientes y géneros de la obra no sólo son quienes se cruzan con él en las peripecias, penurias, ensoñaciones y andanzas del proteiforme protagonista sino los poetas y narradores leídos y asimismo sus personajes, los y las compañeras librescas y literarias, tan presentes y reales o tan fantasmales como los primeros, tan poderosos e influyentes como ellos en el destino del Yo y de sus metamorfosis ficcionales. Si uno de los rasgos propios del lirismo en su acepción tradicional es la apóstrofe a algún destinatario ausente - amada, protector, numen, musa, dios o poeta-, en los poemas de Roberto Bolaño, junto a amigos y amores, se apersonan en vocativos autores como el escritor de ciencia-ficción Alfred Bester que imaginó la "universidad desconocida", los "admirables poetas troyanos" de la antología de los Líricos griegos arcaicos de Gabriel Ferraté o el juglar satírico Peire Cardenal y el trovador político Guiraut de Bornelh que se mueve a la vez como personaje e interlocutor. La circunstancia del Yo se desdobla entonces $y$, difuminado lo inmediato, se confunde con la del otro

\footnotetext{
${ }^{4}$ Véase Roberto Bolaño, La Universidad Desconocida, op. cit.: "San Roberto de Troya", título de una sección de La Universidad desconocida, pp. 95-126, que a su vez incluye un poema así titulado, p. 113; "Devoción de Roberto Bolaño", p. 397; "El regreso de Roberto Bolaño”, pp. 398-399; “Los años”, pp. 401-402.
} 
-escritor - en escenarios medievales o antiguos, en lugares imaginarios y alegóricos como la "sala de lecturas del infierno". Así, el poema puede tornarse billete de agradecimiento dirigido a Alfred Bester en una como leyenda de formación de quien estudia en esa "Universidad Desconocida" donde la vida precaria se conjuga con constantes y muy eclécticas lecturas:

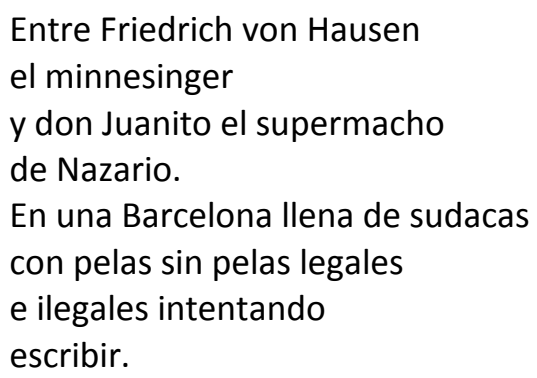

(Querido Alfred Bester, por lo menos he encontrado uno de los pabellones de la Universidad Desconocida!).

(Bolaño, 2007: 163)

No que esta poesía de lo diario y del diario estudio, del cotidiano ir y venir entre lectura y escritura del joven poeta y futuro narrador, prefigure la ulterior redacción de una suerte de "Leyenda de Duluoz" al modo de Jack Kerouac ni busque la prosa espontánea que anheló y halló el poeta de la Beat Generation sino que narra o esboza croquis de momentos y percepciones, se hace vademécum y compañera del Yo a la vez que conversación literaria y coloquial con los demás, sean destinatarios aludidos, sean los probables o improbables lectores de los poemas. Si, recordémoslo, el término de Universidad remite al saber universal, también ha de entenderse aquí como comunidad universal, entre los lectores y los escritores, entre los vivos y los muertos, entre los imaginados y los presentes, en esa perpetua lucha del escritor o más bien de la escritura - o sea, por antonomasia bolañesca, de la poesía-, con el Tiempo y la Nada o el Vacío a los que una y otra vez se referirá Roberto Bolaño en su incipiente e interrumpida madurez. ${ }^{5}$ El Yo lee, recibe enseñanzas, escribe y comenta, se hace transmisor en ese aprendizaje compartido de la vida poética, pues van a la par vida, lectura y escritura.

Más tarde en la vida/obra del escritor, cuando Roberto Bolaño se dedica a escribir los cuentos recogidos en Llamadas telefónicas, Putas asesinas, El gaucho insufrible, o los que se publicaron póstumamente en $E I$ secreto del mal, se metamorfosea la interpelación lírica a otros escritores, perdurando bajo formas que la trasponen en estrategias declaradamente narrativas y memoriosas. Ya no invoca el Yo a los clásicos o los distantes desconocidos sino que un Yo narrador recuerda, escenifica y narra sus

\footnotetext{
${ }^{5}$ Véase, por ejemplo, el inicio del capítulo 23 de Los detectives salvajes, Barcelona, Anagrama, 1998, o "Intento de agotar a los mecenas" y "Un narrador en la intimidad" en Entre paréntesis, op. cit., pp. 193-195 y 321-323.
} 
relaciones y afinidades con algunos maestros a la sazón vivos. Si bien "Sensini", primer cuento de Llamadas telefónicas, le atribuye un nombre ficticio al argentino Di Benedetto, la narrada relación epistolar entre los dos latinoamericanos exiliados -el joven y desconocido narrador, su corresponsal ya famoso aunque necesitado de dinero y desatendido en España - se inscribe en cierto modo en la interlocución con los escritores leídos y admirados que practicaba el poeta a inicios de los ochenta. Sólo que aquí en modo alguno es imaginario el intercambio, y el cuento refiere con afilada irrisión y desolación la complicidad y alianza entre el joven y el mayor, reducidos ambos a concursar con sendas obras, y no sin trampas, en certámenes literarios de provincias. "Sensini" que, desde luego, abre a otros vericuetos propios de las historias de dos generaciones de latinoamericanos exiliados en tiempos de dictaduras, gira con humor en torno a la miseria del mundo literario. Por lo demás el propio Bolaño definió este cuento como una suerte de instalación puesto que con él ganó un concurso literario similar a los referidos en el argumento, hecho que precisa una nota final tras el relato. El gesto estético vanguardista que impulsa la ficción a ejercer su poder fuera de los límites de lo escrito, dentro de la misma realidad, se conjuga con la evocación/invocación de un escritor por otro en una historia ejemplar de destinos literarios. En "Sensini" la ficción, o más propiamente la autoficción, logra sortear con seguridad los riesgos de efusión del lirismo sin por ello renunciar a un patetismo pudoroso y apenas ironizado aunque sí distanciado. Entre otros detalles, una réplica revela cómo la hija del ya difunto Sensini sorprende las lágrimas del narrador al oír éste que el escritor murió, sin gozar de mayor reconocimiento, poco después de volver a la Argentina donde buscó en vano a su hijo desaparecido. La direccionalidad múltiple de la prosa narrativa autoriza aquí la discreción elegíaca a la vez que procura, por obra y gracia del juego, un triunfo cierto aunque diminuto y pasajero ante la adversidad de lo real.

La relación epistolar del joven poeta con otro mayor que él asoma, señalada esta vez directamente como recuerdo autobiográfico, en un cuento de Putas asesinas que narra el encuentro del narrador con el fantasma de Enrique Lihn en una pesadilla fechada de 1999, sin duda poco después del regreso de Bolaño a Chile tras veinticinco años de ausencia. ${ }^{6}$ De nuevo, la referida correspondencia pertenece al periodo de formación del Yo - "estoy hablando del año 1981 o 1982" (Bolaño, 2001: 218), dice- y el cuento se asume como agradecimiento al ya difunto Lihn a la vez que como despedida de su fantasma, reflexión melancólica y humorística sobre los poetas chilenos de la propia generación y narración onírica entre burlesca y siniestra, o sea libre interpretación poética, de los tiempos de la historia chilena, literaria y política, durante y después de la dictadura. Lihn es fantasma y fantasma asimismo es la dictadura cuya atmósfera sigue

\footnotetext{
${ }^{6}$ Véase "Fragmentos de un regreso al país natal" y "El pasillo sin salida aparente" en Entre paréntesis, op. cit., pp. 59-78.
} 
habitando Santiago. La ficción ronda lo autobiográfico, aquí subvertido por el imaginario onírico, o mejor dicho lo inserta en la ficción que lo prolonga, ofreciéndole ecos por encima del tiempo transcurrido entre 1981 y 1999 . Y si este "Encuentro con Enrique Lihn" no se presenta como diario, al modo de los poemas del periodo barcelonés de Bolaño, se inscribe en la acepción amplia de las escrituras del Yo, recordando aquella época de formación, penurias y aventuras en un asomo de memorias que hace dialogar dos tiempos, recorrido así el trecho entre varios momentos de la vida y la obra, entre la época del predominio de la poesía y aquella en que prevalece la publicación de cuentos y novelas.

En "Carnet de baile", otro cuento de Putas asesinas, que ordena en forma de juego y en 69 secuencias numeradas un recuento de la formación poética del Yo narrador y de sus motivos para no bailar al son de Neruda ni elegirlo como pareja de baile, se altera y casi desaparece la escenificación de la interlocución con algún maestro, y si la hay, en todo caso resulta fallida. Permanece lo narrativo, si bien presente en la obra poética, intensificado y ampliado en esos relatos que convierten la agradecida anotación del inmediato aprendizaje en elaboración irónica y reflexiva de una historia de lecturas, tanteos y descubrimientos de posibles maestros, historia entrelazada con el recuerdo de las aventuras y desventuras del poeta adolescente en México y del veinteañero en el Chile del golpe de Estado. Permanece la visión onírica, que aquí convoca a un desternillante y grotesco Neruda aparecido, tras Hitler, en sucesivas noches de pesadilla e incapaz de comunicarse con el narrador. Permanece la autobiografía vital, literaria y crítica e incluso la autocrítica. "Carnet de Baile", cuyo relato condensa años de vida del narrador, años de historia política y literaria chilena, y que se da el lujo de intercalar relatos secundarios en su tensa brevedad, también puede leerse como manifiesto y como ejercicio rítmico. Determinante, el ritmo sostiene el humor y la ironía, amén de tener los visos persuasivos de un alegato acusatorio. Pues la figura aquí exorcizada y en parte redimida tras verse sometida al escarnio y la denuncia es la de Neruda, inevitable astro de la poesía chilena y del sórdido engaño que pudo llegar a ser, a ojos del narrador, la poesía de la izquierda latinoamericana. Del manifiesto, y no de cualquiera sino del primer manifiesto surrealista de André Breton de 1924, el carnet de baile ha pedido prestado una forma sintáctica que, aquí, señala la pertenencia a la corriente poética inaugurada por tal o cual maestro. Allí donde Breton releía a los poetas anteriores al surrealismo para afiliarlos retroactiva y lúdicamente al incipiente movimiento, afirmando que "Swift es surrealista en la maldad / Sade es surrealista en el sadismo / [...] Hugo es surrealista cuando no es tonto / [...] Poe es surrealista en la aventura / Baudelaire es surrealista en la moral" (Breton [1924] 2005: 37; la traducción es nuestra), el narrador autobiográfico de Bolaño escande su relato con un aleatorio y furtivo estribillo que define las posturas de unos y otros -la propia, la de los poetas de su generación y de la siguiente-, con algún rasgo 
ético, estético y existencial de la obra de Neruda, Parra, Huidobro, De Rokha, Mistral, Vallejo:

22. Los poetas mexicanos de entonces que eran mis amigos y con quienes compartía la bohemia y las lecturas se dividían entre vallejianos y nerudianos. Yo era parriano en el vacío, sin la menor duda. [...] 46. Parejas de baile de la joven poesía chilena: los nerudianos en la geometría con los huidobrianos en la crueldad, los mistralianios en el humor con los rokhianos en la humildad, los parrianos en el hueso con los lihneanos en el ojo. (Bolaño, 2001: 201 y 213)

El uso del ritornello; la asociación certera e incongruente que conjuga los adjetivos derivados de los apellidos de los poetas del canon chileno o latinoamericano con alguna propiedad de sus obras, trastocándolas a veces; la coreografía que empareja a los unos con los otros y convierte al nuevo canon en burlesco salón de baile y al narrador en maestro de guiñolescas ceremonias alían aquí la habilidad satírica a una intensidad poética juguetona que caracteriza al Bolaño maduro. En este y otros relatos de la época se muestra a la vez heredero y huérfano de los maestros que supo elegirse y dueño de la prodigiosa destreza narrativa del cuentista y novelista iluminado por el lirismo prosaico del poeta. "Carnet de baile" parece desplegar todos los argumentos que, en contra de los "héroes / de la poesía lírica / y del balancín de la muerte", insinuaba el joven poeta a fines de los setenta.

Ya se sabe que así en las novelas breves de Bolaño como en las vastas, ramificadas y voluminosas la invocación lírica a los poetas se metamorfosea en historias enigmáticas de escritores enigmáticos, poetas criminales, imaginarios mamarrachos de la literatura de ultraderecha, pobres poetas desaparecidos, fracasados, suicidados o desatendidos, épica jocosa, desoladora, de la vida poética de los infrarrealistas convertidos en ficticios viscerealistas. Tal parece que el novelista y cuentista responde airoso, pero curtido por el constante aprendizaje de la ironía como antídoto de la ingenuidad lírica, a una de las consignas del manifiesto infrarrealista que firmó en 1976: "Un nuevo lirismo, que en América Latina empieza a crecer, a sustentarse en modos que no dejan de maravillarnos. La entrada en materia es ya la entrada en aventura: el poema como un viaje y el poeta como un héroe develador de héroes" (Bolaño, [1977] 2009: 143). El narrador de los cuentos y las novelas será héroe enmascarado cuando no invisible, develador de héroes mas sobre todo de antihéroes, que a menudo son los mismos, la entrada en la aventura no será ya la del Yo sino la de los personajes. Porque, desde luego, por más narrativa que sea la poesía en verso de "Los neochilenos", Los perros románticos y El último salvaje; o la poesía en prosa de "Gente que se aleja, "Prosa de otoño en Gerona", "Un 
paseo por la literatura", 7 en la obra poética la economía de la alianza entre lo narrativo y lo ficcional dista de ser la desplegada en las ulteriores o contemporáneas novelas y libros de cuentos.

Recogido como conjunto poético en La Universidad Desconocida, "Gente que se aleja" se presenta sin embargo como un montaje de fragmentos tan cercano a la novela que se publicó primero como tal, con mínimas diferencias, bajo el título de Amberes. La ubicua Amberes, escrita en 1980 y aparecida veintidós años después, a favor de la incipiente celebridad de su autor tras los dos premios recibidos por Los detectives salvajes, el Rómulo Gallegos y el Herralde de novela, demuestra con creces que, paralelamente a la obra poética en verso del periodo barcelonés, Bolaño ensayaba una escritura en prosa del todo híbrida. Al fundirse lo narrativo ficcional con la poesía en unas secuencias provistas de títulos y cuya consecución no obedece a necesidades dramáticas, los fragmentos de lo que más adelante se llamaría Amberes dibujan y desdibujan alternadamente varios asomos de tramas narrativas, desdoblan los planos de representación, se alejan de lo autobiográfico y regresan a él. En una distanciación irónica aún inestable del Yo, aparece, alternado con identidades como "el escritor" o "el autor", un personaje llamado Roberto Bolaño o se menciona al "pobre Bolaño escribiendo en un alto en el camino". Uno de los fragmentos se dirige, a modo de poema-carta, a una destinataria llamada Lisa a quien, en otro fragmento, el narrador define como una "enfermedad secreta" y cuyo nombre recuerda a la muy real Lisa Johnson, que formó parte del movimiento infrarrealista y fue el primer amor del autor. Dos fragmentos titulados "Cuando niño" y "El mar" comparten con el poema "Mi poesía", recogido en La Universidad Desconocida, la evocación de un sueño infantil, ilustrado con dibujos, en torno a un barquito que navega por el mar. Esté presente o ausente el barquito, el mar en calma, el mar movido por un suave oleaje o agitado por temibles olas de tempestad se representa con sendas líneas - una recta, otra ondulada y otra quebrada - tal y como reaparecerá, en los Detectives salvajes, convertido en el único poema conocido, visual y vanguardista, de la ficticia poeta viscerrealista de los años veinte, Cesárea Tinajero. Más allá del viaje de la representación escrita y dibujada de ese sueño infantil a través de varios libros en los que cobra distintos valores y sentidos según su grado de ficcionalización, el parentesco entre sus primeras apariciones en la obra incita a leer "Mi poesía" como un arte poética que ilustra Amberes/ "Gente que se aleja" y, a no ser por su escritura en verso, ese poema podría incluso leerse como un fragmento desprendido de la novela o poemario en prosa. Amén de declarar intenciones estéticas, "Mi

\footnotetext{
7 Roberto Bolaño, "Prosa de otoño en Gerona”, "Los neochilenos", "Un paseo por la literatura", Tres, Barcelona, El acantilado, 2000; Los perros románticos, Barcelona, Lumen, 2000; El último salvaje, México, Al este del paraíso, 1995; "Gente que se aleja", La Universidad Desconocida, op. cit. Los poemas incluidos en los tres primeros títulos citados se hallan en su mayoría recogidos entre las distintas secciones de La Universidad Desconocida.
} 
poesía" comparte con Amberes/"Gente que se aleja" varios personajes -el poli, el jorobadito, Lisa-, alude a una trama policial, escoge modos de enunciación dubitativa. En sus versos iniciales, la voluntad de "decir", que no la de narrar, corre paralela con la ambición de dar a ver, en todo caso apela el poema a un proyecto de expresión capaz de organizar metafóricos planos sobreimpuestos: "Mi poesía temporada de verano de 1980/ sobreimposición de dos cines dos películas/ sobreimpuestas quiero decir el jorobadito el poli/ en planos similares quiero decir el barquito" (Bolaño, 2007: 27). Como posible realización de ese deseo, Amberes, antes que hilvanar tramas, entrelaza escenas vistas, soñadas, filmadas, proyectadas en una improvisada pantalla por personajes de cambiante identidad entre quienes se mueve un Yo narrador dispuesto a pasarse a la tercera persona. La enunciación traduce el mismo fenómeno de escisión del Yo al entrecomillar frases de difícil atribución que, sin embargo, podrían entenderse como las del Yo/Él. Obras como ésa suelen llamarse "experimentales", y en la búsqueda de Bolaño Amberes aparece como un texto en fermentación, como un ente literario polimorfo - lírico, prosaico, narrativo, ficcional, prendado de lo visualcomo una novela embarazada de sí misma, aún nonata y sin embargo nacida. En la introducción que escribió en 2002 para la publicación del conjunto como novela, Bolaño evoca la tendencia original del texto a "multiplicarse y a reproducirse como una enfermedad" y aclara el doble desprecio que en el año 1980 le provocaban casi por igual la "literatura oficial" y la "literatura marginal". Y agrega: "Pero creía en la literatura: es decir no creía ni en el arribismo ni en el oportunismo ni en los murmullos cortesanos. Sí en los gestos inútiles, sí en el destino. Aún no tenía hijos. Aún leía más poesía que prosa" (Bolaño, 2002: 10).

Obra del libre escribir entre poesía y novela, escrita, a decir de su autor, "para los fantasmas" más aún que para él mismo, Amberes no vacila ante el lirismo autoconfidencial, la indiferencia por la legibilidad de los argumentos, el montaje de fragmentos a menudo inconexos, la directa elegía, dedicada por ejemplo a la suicidada poeta belga Sophie Podolski, y asimismo anuncia muchos de los rasgos que animarán los ulteriores cuentos y novelas de Bolaño. En ellos la pesquisa de la trama policial se torna a veces investigación literaria y se hace principio de tensión dramática cuya suspensión desemboca en irresueltos enigmas; la elegía, directa o indirecta, permanece como constante; el montaje de metafóricos planos superpuestos se convierte en las percepciones alternas y poéticas de la realidad que alcanzan inspirados personajes en sus sueños, visiones y alucinaciones; la fragmentación se maneja como recurso rítmico y dramático al servicio de las bifurcaciones de los argumentos; las voluntarias incertidumbres de la enunciación llegan en Los detectives salvajes a transmutarse en portentosa abundancia de precisas voces narradoras o, en 2666, se metamorfosean en manifestaciones sonoras de voces fantasmales -inquietantes y en ocasiones comiquísimas-; en algunos cuentos la pasión por lo visual y, en especial, por la fotografía y lo cinematográfico, se traduce en laberintos 
narrativos surgidos de la contemplación de la foto de un grupo de escritores o de secuencias de fotos, y en resúmenes de películas visionadas por un narrador que las interpreta. ¿Y qué del lirismo?

El lirismo permea todos y cada uno de los rasgos de la prosa narrativa. Divorciado ya del desinterés por la legibilidad dramática de los argumentos, arrebatado a la directa expresión del Yo, el lirismo se presta, con tierna ironía, a determinados personajes, e incluso a un Yo autoficcional, y se transfiere a los modos narrativos, que se asientan en un infalible manejo del ritmo, un uso constante de la metáfora sorpresiva, a veces hilada, a veces partícipe de una reinventada construcción alegórica. La anáfora y la poética de la lista sirven la velocidad de los relatos, se hacen dúctiles recursos acentuales de los afectos experimentados por los personajes, provocan efectos de asombro o de sutil ironía. Los juegos taxonómicos clasifican en rítmicos derroches de humor e irreverencia patologías mentales, aseveradas o no por la psiquiatría, o poetas del canon de la literatura latinoamericana y española según su supuesto ethos homosexual. Estas estrafalarias y deslumbrantes listas a menudo reiteran como miniaturas las formas rítmicas mayores que rigen el conjunto de un relato, como el treno prosaico y ejemplar de esa novela negra del horror y del negrísimo humor que alcanza a ser "la parte de los crímenes" en 2666. La tentación vanguardista de la poesía visual minimalista se inserta en juegos y adivinanzas que, desde su paródica y seria gracia infantil, invitan a una política lúdica de la lectura y conceptualizan una poética de lo inconcluso, elogiando la pieza faltante del rompecabezas que llega a ser una novela de aventuras, literarias, viajeras, eróticas, políticas y libertarias, como Los detectives salvajes. En ésta, la épica de la poesía vanguardista a la que, resuelto, apelaba el Bolaño autor de uno de los tres manifiestos infrarrealistas se narra y canta en modo coloquial para una ficticia "Leyenda de Duluoz" del que Duluoz habría sido eliminado como narrador para ser objeto de las narraciones de sus compañeros de aventuras. El efecto de mitificación de la gesta juvenil se torna así ambiguo, sublimes y ridículas las tribulaciones de los jóvenes héroes y poetas, certera la vindicación de los gestos inútiles de la vida poética ante la miseria de la "literatura oficial", exorcizada la parte mortífera de la utopía política.

Lo infrarreal, lo surreal no desaparecen de las ficciones sino que las habitan como clandestinos agentes poéticos que surgen en las descripciones, en la suplantación de los elementos realistas por su interpretación alucinada, visionaria, onírica que insinúa la inminencia del peligro en la acción, la inminencia de la resolución de un enigma, la promesa de una revelación, el desconcertante placer de su elusión.

Bordeando el abismo del mal, como tanto se ha comentado, el abismo, para ser más exactos, del horror político y moral en sus históricas manifestaciones contemporáneas, aproximándose sin cesar al abismo donde zozobra y renace el sentido, a las turbias relaciones entre el arte y el crimen, la obra de ficción de Roberto Bolaño se mete, como la de los maestros de la novela que citaba, por esas ignotas sendas que sólo explora la poesía, 
porque sólo la poesía, así sea novela, soporta la ausencia de respuesta, el peligro y la belleza del misterio. Así dicho, la empresa parecería ser heroica, metafísica, casi solemne. Uno de los secretos de la fórmula "poesía + novela = poesía", sin embargo, es el humor, otro, la invitación al placer que nos dirige, a nosotros, los hipócritas lectores, los semejantes, los hermanos del Yo disuelto en sus ficciones.

\section{Bibliografía}

ANAYA, José Vicente; YÉPEZ, Heriberto (2006), "Los infrarrealistas... Testimonios, manifiestos y poemas", en Replicante, vol. III, n.ㅇ 9, Guadalajara (Jal.), pp. 135-147.

BolaÑO, Roberto ([1977] 2006), "Manifiesto infrarrealista", primera publicación en Correspondencia Infra 1. Revista menstrual del movimiento infrarrealista, México, octubre/noviembre de 1977. Republicado en: "Los infrarrealistas... Testimonios, manifiestos y poemas", ANAYA, José Vicente y YÉPEZ, Heriberto (2006), Replicante, vol. III, n. 09, Guadalajara (Jal.), pp. 142-144.

(1995), El último salvaje. México, Al este del paraíso. (1998), Los detectives salvajes. Barcelona, Anagrama.

(1999), Entrevista filmada del programa televisivo "La belleza de pensar", dirigido y conducido por Cristian Warnken, Estación Mapocho. Disponible en "Archivo Bolaño". Consultado el 27 de agosto de 2012 en http://garciamadero.blogspot.mx,2008/05 (2000a), "Prosa de otoño en Gerona", "Los neochilenos", "Un paseo por la literatura", Tres. Barcelona, El acantilado.

(2000b), Los perros románticos. Barcelona, Lumen. (2001), Putas asesinas. Barcelona, Anagrama. (2002), Amberes, Barcelona. Anagrama. (2004a), 2666, Barcelona. Anagrama. (2004b), Entre paréntesis. Barcelona, Anagrama. (2007), La Universidad Desconocida. Barcelona, Anagrama.

BRETON, André (2005), "Manifeste du surréalisme (1924)", Manifestes du surréalisme. París, Gallimard, Folio/ Essais 5.

ECHEVARRía, Ignacio (2004), "Nota a la primera edición", en BolaÑo, Roberto, 2666. Barelona, Anagrama.

PARRA, Nicanor (1985), Hojas de Parra, Santiago de Chile, Ganímedes.

WARNKEN, Cristian (director y conductor) (2008), Programa "La belleza de pensar", Estación Mapocho. Disponible en "Archivo Bolaño". Consultado el 27 de agosto de 2012 en http://garciamadero.blogspot.mx,2008/05

YÉPEZ, Heriberto (2009), "Historia de algunos infrarrealismos", El coloquio de los perros. Revista de literatura. Monográfico infrarrealismo (2), Consultado el 30 de agosto de 2012 en http://www.elcoloquiodelosperros.net/numeroinfra/infarthe.html 